\title{
ВОЗНИКНОВЕНИЕ И РАЗВИТИЕ ДОМАШНЕГО АРЕСТА КАК МЕРЫ ПРЕСЕЧЕНИЯ В РОССИЙСКОМ УГОЛОВНОМ СУДОПРОИЗВОДСТВЕ
}

\section{THE EMERGENCE AND DEVELOPMENT \\ OF HOUSE ARREST AS A PREVENTIVE MEASURE IN RUSSIAN CRIMINAL PROCEEDINGS}

V. Firsov

Summary: The article analyzes the evolution of legal regulation of a preventive measure in the form of house arrest from the beginning of its generation - the Code of Laws of the Russian Empire in 1832 to the current state of legal regulation the Code of Criminal Procedure of the Russian Federation, it considers the historical experience of applying and reforming this Law Institute, the practice of applying this preventive measure use all positive at the current time. In addition, the article draws attention to the need to further improvement of regulation of the procedure for electing this preventive measure, the execution of a court decision on the choice of house arrest, as well as monitoring the implementation of prohibitions imposed by the court on the suspect or accused in order to increase the effectiveness of this preventive measure.

Keywords: preventive measure; house arrest, election, reasons of application, suspect, accused, isolation from society, control.
$\mathrm{P}$ азвитие и движение вперед возможно только при знании своего исторического прошлого. «В процессе познания правовых норм и институтов необходимо учитывать, что при любом реформировании нельзя рассчитывать на положительные результаты без знания и учета истории объекта реформирования, условий и этапов пути, приведшего его к существующему состоянию»[1].

Изучение истории развития мер пресечения, в том числе домашнего ареста, необходимо для того, чтобы учесть весь накопленный исторический опыт правового регулирования названного института, практики избрания и применения мер пресечения и взять все положительное для использования в настоящее время.

Перечень мер пресечения, их строгость и основания избрания на различных этапах развития общества, зачастую связаны с политическим строем, существующем в государстве в определенную историческую эпоху. И.Я. Фойницкий по данному поводу отмечал: «В истории уголовного процесса энергия мер пресечения всегда стояла в обратном соотношении с развитием гражданской
Фирсов Владимир Григорьевич Независимый исследователь firsov_vg65@mail.ru

Аннотация: В статье проведен анализ эволюции правового регулирования меры пресечения в виде домашнего ареста от начала его зарождения - Свода законов Российской империи 1832 г. до современного состояния в УПК РФ, рассмотрен исторический опыт применения и реформирования названного института, практика применения данной меры пресечения с целью использования всего положительного в настоящее время. Кроме того, в статье обращено внимание на необходимость дальнейшего совершенствования регламентации порядка избрания и применения домашнего ареста в целях повышения эффективности применения данной меры пресечения.

Ключевые слова: мера пресечения; домашний арест, избрание, основания применения, подозреваемый, обвиняемый, изоляция от общества, контроль.

свободы»[2].

Впервые на законодательном уровне домашний арест был урегулирован в Своде законов Российской империи 1832 г. (ст. 876, т. XV). Перечень мер пресечения включал в себя:

1. содержание в тюрьме и при полиции;

2. домашний арест;

3. полицейский надзор;

4. отдачу на поруки[3].

В Своде законов предусматривалась необходимость учитывать при избрании меры пресечения такие обстоятельства, как причастность лица к совершению преступления, тяжесть преступления, звание обвиняемого и большее или меньшее подозрение в намерении учинить побег.

В домашнем аресте и полицейском надзоре Свод законов предлагал содержать обвиняемых в преступлениях менее важных, за которые они подлежали бы тюремному, на известное время, заключению (ст. 878). В 1857 году в ч. 2 т. XV Свода законов были внесены изменения, 
согласно которым в домашнем аресте и полицейском надзоре надлежит содержать обвиняемых в преступлениях менее важных, за которые они подлежали бы заключению в крепости, в смирительных домах или тюрьме[4].

Сравнение и анализ статей 134, 135 и 137 ч. 2 т. XV Свода законов позволяет констатировать неопределенность в части того, какую именно меру пресечения (домашний арест, полицейский надзор или отдачу на поруки) можно было избирать в отношении обвиняемых. Выбор одной из этих трех мер пресечения был отдан на усмотрение полиции.

В связи с этим А.Ф. Кистяковский считал, что с «изданием Свода законов не было осуществлено правило, на основании которого принятие меры пресечения должно зависеть от точного определения закона, а не от произвола и усмотрения судьи, а тем более полиции»[5]. Относительно практики применения мер пресечения в этот период Н.Н. Розин отмечал: «так как действия органов, уполномоченных на принятие принудительных мер не подлежали в ту пору никакому контролю и никаких способов обжаловать не существовало, то все применяемые в процессуальных целях меры приобрели чисто полицейский характер»[6].

Домашний арест, в основном, применялся в начале досудебного производства. Например, дворяне Виноградовы, отец и сын, обвиняемые в убийстве, первый жены, второй - матери, на начальном этапе следствия содержались под домашним арестом в собственном доме[7].

Домашний арест состоял в том, что в доме обвиняемого находился полицейский служащий или жандарм. Применение данной меры пресечения было ограничено вследствии невозможности для каждого обвиняемого иметь дома полицейского служащего или жандарма, в связи с чем домашний арест был предназначен для немногих, а именно для лиц дворянского сословия.

С изданием Устава уголовного судопроизводства 1864 года был расширен перечень мер пресечения[8]. Он включал в себя следующие меры пресечения:

1. отобрание вида на жительство или подписка о явке к следователю и неотлучке с места жительства (п. 1 ст. 416);

2. отдача под особый надзор полиции (п. 2 ст. 416);

3. отдача на поруки (п. 3 ст. 416, ст.ст. 422, 424-426);

4. взятие залога (п. 4 ст. 416, ст.ст. 423-427);

5. домашний арест (п. 6 ст. 416, ст. 428);

6. взятие под стражу (п.6 ст. 416, ст.ст. 417-419, ст. 430).

Статьей 421 предусматривались обстоятельства, которые надлежало учитывать при избрании мер пресече- ния: «При избрании меры к пресечению обвиняемому, способов уклоняться от следствия, принимаются в соображение не только строгость угрожающего ему наказания, но также и сила представляющих против него улик, возможность скрыть следы преступления, состояние здоровья, пол, возраст и положение обвиняемого в обществе». Анализ указанных положений показывает некоторое сходство с современными положениями ст. 99 УПК РФ.

Устав уголовного судопроизводства 1864 г. впервые предусматривал возможность обжалования обвиняемым постановления судебного следователя о применении мер пресечения во вторую инстанцию - окружной суд (ст. 493). При этом, в обжаловании меры пресечения и рассмотрении жалобы в суде защитник не участвовал.

М.В. Духовской считал, что домашний арест в тот период имел редкое применение в виду трудности осуществить его. «Способ применения не выяснен в законе. Поэтому, подобно полицейскому надзору, он выполняется различно. Некоторые находят возможным ограничится отобранием подписки о невыходе из занимаемого помещения, причем нарушение подписки влечет за собой наказание. Другие справедливо полагают, что этого недостаточно, а надо приставить к дому стражу и воспретить выход. Домашний арест имеет смысл в тех случаях, где следовало бы подвергнуть заключению, а между тем применить его нельзя, например, при тяжкой болезни обвиняемого, недостатке мест заключения, семейном положении (мать кормит грудью и т.п.)»[9].

По мнению П.И. Люблинского, домашний арест рассматривался как привилегированная форма взятия под стражу. Он применялся в весьма редких случаях, обычно на короткие сроки, до представления залога или поручительства. Эта мера почти не находила себе применения из-за нехватки караульной стражи[10]. Так, по статистическим сведениям, в 1898 г. в общих судебных установлениях было применено мер пресечения (табл.1)[11]:

Таблица 1

\begin{tabular}{|c|l|l|l|}
\hline $\begin{array}{c}\text { № } \\
\text { п/п }\end{array}$ & \multicolumn{1}{|c|}{ Меры пресечения } & $\begin{array}{c}\text { Число } \\
\text { осужден- } \\
\text { ных }\end{array}$ & $\begin{array}{c}\text { Процентное } \\
\text { соотншение } \\
\text { от числа } \\
\text { осужденных }\end{array}$ \\
\hline 1 & Содержание под стражей & 16836 & 34,5 \\
\hline 2 & Домашний арест & 2 & 0,0 \\
\hline 3 & Взятие залога & 452 & 0,9 \\
\hline 4 & Отдача на поруки & 2240 & 4,6 \\
\hline 5 & Отдача под надзор полиции & 11578 & 23,7 \\
\hline 6 & $\begin{array}{l}\text { Отобрание вида на жительство } \\
\text { или подписки о неотлучке }\end{array}$ & 9605 & 19,8 \\
\hline 7 & Отдача под ответственный надзор & 57 & 0,1 \\
\hline
\end{tabular}


Из представленных статистических данных следует, что мера пресечения в виде домашнего ареста практически не избиралась в уголовном судопроизводстве России, при этом содержание под стражей являлось самой распространенной мерой пресечения.

Таким образом, основными недостатками, препятствовавшими эффективному применению меры пресечения в виде домашнего ареста, предусмотренной Уставом уголовного судопроизводства 1864 г., являлось отсутствие законодательной регламентации оснований, условий и пределов применения данной меры пресечения, а также процедуры ее применения и механизма контроля за ее исполнением.

Система мер пресечения, закрепленная в Уставе уголовного судопроизводства, оставалась неизменной практически до 1917 г. Принятый 24 ноября 1917 г. Декрет о суде № 1 прекратил действия таких мер, как отобрание вида на жительство и особый надзор полиции, в остальном же изменений не произошло[12]. «Положение о народном суде», принятое 30 ноября 1918 г., запретило следственным и судебным органам использовать ссылки на законы свергнутых правительств[13].

25 мая 1922 г. Постановлением Всероссийского Центрального исполнительного комитета (ВЦИК) был принят первый Уголовно-процессуальный кодекс РСФСР, в котором мерам пресечения была посвящена глава XII. Статья 147 УПК РСФСР содержала следующий перечень мер пресечения:

1. подписка о невыезде;

2. поручительство, личное и имущественное;

3. залог;

4. домашний арест;

5. заключение под стражу[14].

УПК РСФСР 1922 г. предусматривал меру пресечения в виде домашнего ареста (ст. 160)[15], которая заключалась в лишении обвиняемого свободы в виде изоляции его на дому с назначением стражи или без таковой. В исключительных случаях домашний арест мог избираться в отношении подозреваемого, однако в этом случае обвинение должно было быть предъявлено не позднее 14 суток со дня избрания, иначе мера пресечения отменялась. Отмена или изменение меры пресечения допускались после первого допроса обвиняемого (ст. 148 УПК РСФСР 1922 г.).

О применении меры пресечения следователь выносил мотивированное постановление, содержащее сведения о совершенном преступлении и оснований применения меры пресечения, о чем незамедлительно уведомлялся обвиняемый (ст. 149 УПК РСФСР 1922 г.). При этом, под основаниями понимались сведения о наличии опасения, что обвиняемый скроется от следствия и суда, или же при наличии достаточных оснований полагать, что обвиняемый, находясь на свободе, будет препятствовать раскрытию истины (ст. 161 УПК РСФСР 1922 г.).

В соответствии со ст. 150 УПК РСФСР 1922 г., при решении вопроса о необходимости избрания и виде меры пресечения следователь должен был учитывать важность преступления, приписываемого обвиняемому, тяжесть имеющихся против него улик, вероятность возможного со стороны обвиняемого уклонения от следствия и суда или препятствования раскрытию истины, состояние здоровья обвиняемого, род занятий и иные обстоятельства.

15 февраля 1923 г. постановлением ВЦИК было принято постановление «Об утверждении Уголовно-процессуального кодекса РСФСР». Данный закон не внес существенных изменений в регламентацию домашнего ареста.

Постановлением ВЦИК от 16 октября 1924 г. «О дополнениях и изменениях Уголовно-процессуального кодекса РСФСР» органам дознания было предоставлено право избирать любую меру пресечения после допроса ими лица, подозреваемого в совершении преступления, за которое может быть назначено наказание в виде лишения свободы на срок свыше одного года[16]. Об избрании меры пресечения орган дознания уведомлял следователя, в участке которого состоял орган дознания.

По поводу меры пресечения в виде домашнего ареста, предусмотренной УПК РСФСР 1923 г., П.И. Люблинский сделал следующие выводы:

1. Домашний арест не должен быть понимаем в смысле абсолютного запрещения выхода лица из занимаемого им помещения. Если такой арест сопряжен с назначением стражи, то отлучки из дома возможны с разрешения следователя и в сопровождении стражи. Если стражи не установлено, то домашний арест может быть ограничен обязанностью нахождения в доме в течение вечерних и ночных часов.

2. Эта мера пресечения не есть наказание, и пребывание дома должно обеспечивать лишь возможность постоянного надзора нахождения лица на месте, а не лишать его средств посещать место работы, или снискивать себе заработок в течение дня, или вести свои хозяйственные дела вне дома.

3. В отличие от подписки о невыезде, домашний арест прикрепляет лицо не только к определенному району или городу, но и к определенному помещению.

4. Оплата расходов по содержанию стражи при домашнем аресте производится за счет казны, если сам обвиняемый не изъявит готовности принять их на себя. 
5. Домашний арест является мерой, пригодной в отношении несовершеннолетних обвиняемых, поскольку надзор родителей может явиться недостаточной гарантией реального соблюдения этой меры; совершеннолетних, которые тяжело больны и лишены возможности отлучаться из дому; беременных или кормящих грудью женщин; лиц, заслуживающих высокое моральное доверие в обществе»[17].

УПК РСФСР 1923 г. не предусматривал конкретных оснований для избрания мер пресечения, за исключением заключения под стражу (ст. 158), что давало возможность следователям применять данные меры по собственному усмотрению. В связи с данной неопределенностью, М.С. Строгович считал допустимым применение домашнего ареста лишь тогда, когда у следователя или суда нет серьезных оснований опасаться побега, но обвиняемого все же необходимо изолировать, чтобы он не помешал ходу следствия[18].

Основы уголовного судопроизводства Союза ССР и Союзных Республик 25 декабря 1958 г., а в дальнейшем и УПК РСФСР 1960 г. исключили из перечня мер пресечения домашний арест.

Таким образом, как считает К.Т. Балтабаев, домашний арест был предан забвению и незаслуженно забыт, поскольку в новом обществе отрицалась идея политического и экономического неравенства, что однозначно исключало из правотворческой деятельности мысль об индивидуализации мер пресечения в различных формах[19]. Уголовный процесс трактовался исключительно как инструмент борьбы с преступностью, так, В.И. Каминская утверждала, что до тех пор, пока существует преступность, сама постановка вопроса о каком-либо существенном сокращении мер процессуального принуждения вряд ли может быть признана перспективной и плодотворной[20].

Подводя итог, отметим, что домашний арест в период действия УПК РСФСР 1922 и 1923 гг. применялся аналогично правилам Устава уголовного судопроизводства 1864 г. При этом проблемы, касавшиеся отсутствия законодательной регламентации оснований, условий и пределов применения данной меры пресечения, а также процедуры ее применения и механизма контроля за ее исполнением, существовавшие и в Своде законов и в Уставе уголовного судопроизводства, оставались неразрешенными. Указанные проблемы применения домашнего ареста в настоящее время также не разрешены в полном объеме и по УПК РФ.

В тоже время, предусмотренная УПК РСФСР 1923 г. возможность применения домашнего ареста с назначением стражи или без таковой, позволяла избира- тельно гибко применять такую меру пресечения в зависимости от различных обстоятельств.

Принятая в 1991 году Концепция судебной реформы в РСФСР, определяя гарантии прав личности, устанавливала необходимость существенного облегчения условий содержания под стражей до суда и введения новой меры пресечения - домашнего ареста[21].

Необходимость улучшения условий содержания под стражей Ю.Г. Овчинников обосновывал данными о том, что имеющиеся в следственных изоляторах площади позволяют разместить до 140 тысяч человек. На протяжении с 1997 по 2000 г. в СИЗО ежесуточно находилось 270-280 тысяч человек. В ряде случаев на одного человека приходится менее одного квадратного метра, а 33,5 \% не имеют индивидуального спального места и спят по очереди на полу[22].

В юридических изданиях отмечалось, что «такая скученность, вместе с эпидемией туберкулеза создает тяжелые условия нахождения в следственных изоляторах, что создает основания инспекторам Совета Европы приравнивать их к местам пыток.»[23].

В целях сокращения числа лиц, содержащихся в следственных изоляторах, возникла необходимость в мере пресечения, которая бы с одной стороны ограничивала возможность обвиняемого (подозреваемого) скрыться от дознания, предварительного следствия или суда, не позволяла продолжать заниматься преступной деятельностью, угрожать свидетелю, иным участникам уголовного судопроизводства, уничтожить доказательства либо иным путем воспрепятствовать производству по уголовному делу, а с другой стороны не была связана с заключением под стражу.

По мнению А.Е. Григорьевой, домашний арест должен составить альтернативу заключению под стражу, в этом автор усматривала специальную цель данной меры пресечения[24].

Важнейшей вехой судебной реформы в России стал принятый 22 ноября 2001 года Государственной Думой Российской Федерации и одобренный 5 декабря 2001 года Советом Федерации России Уголовно-процессуальный кодекс Российской Федерации, который вступил в силу в основной своей части с 1 июля 2002 года.

Согласно первоначальной редакции ст. 107 УПК РФ, домашний арест заключался в ограничениях, связанных со свободой передвижения подозреваемого, обвиняемого, а также в запрете: общаться с определенными лицами; получать и отправлять корреспонденцию; вести переговоры с использованием любых средств связи. 
В указанной норме не конкретизировалось место нахождения подозреваемого, обвиняемого под домашним арестом, не был указан срок, на который могла избираться данная мера пресечения, не предусматривался запрет пользования информационно-телекоммуникационной системой «Интернет», которая только развивалась в Российской Федерации в момент принятия УПК РФ. Кроме того, норма не содержала возможности использования подозреваемым, обвиняемым телефонной связи в экстренных ситуациях, то есть для вызова скорой медицинской помощи, сотрудников правоохранительных органов, аварийно-спасательных служб, а также для общения с контролирующим органом, дознавателем, со следователем.

В законе не был урегулирован процессуальный механизм применения домашнего ареста, не определены органы и должностные лица, осуществляющие контроль за исполнением подозреваемым, обвиняемым ограничений и запретов, наложенных судом при избрании данной меры пресечения, не был решен вопрос продления ее срока.

Для устранения отмеченных недостатков, породивших многочисленные трудности на практике при избрании и применении меры пресечения в виде домашнего ареста, Федеральным законом «О внесении изменений в Уголовный кодекс Российской Федерации и отдельные законодательные акты Российской Федерации» от 07.12.2011 г. № 420-ФЗ статья 107 УПК РФ была изложена в новой редакции.

Однако, и новая редакция ст. 107 УПК РФ не разрешила многие вопросы применения меры пресечения в виде домашнего ареста. Так, отсутствует четкое и детальное регулирование порядка избрания меры пресечения в виде домашнего ареста, в этих целях в соответствии с ч. 3 ст. 107 УПК РФ применяется порядок избрания меры пресечения в виде заключения под стражу. Кроме того, порядок немедленного исполнения судебного решения об избрании меры пресечения в виде домашнего ареста, а также порядок осуществления контроля за выполнением наложенных судом на подозреваемого, обвиняемого запретов использовать средства связи и информационно-телекоммуникационную сеть «Интернет» в уголовнопроцессуальном законодательстве остаются неурегулированными.

11 февраля 2013 года Федеральным законом «О внесении изменения в статью 107 Уголовно-процессуального кодекса Российской Федерации» № 7-Ф3 были внесены изменения, согласно которым, в срок домашнего ареста засчитывается время содержания под стражей. При этом совокупный срок домашнего ареста и содержания под стражей не должен превышать предельный срок содержания под стражей.
Очередная попытка улучшения правового регулирования избрания и применения домашнего ареста была осуществлена в 2018 году. Согласно внесенным в ст. 107 УПК РФ изменениям, домашний арест заключается в нахождении подозреваемого или обвиняемого в изоляции (при этом, по сравнению с предыдущей редакцией, из нормы были исключены слова «полной либо частичной») от общества в жилом помещении, в котором он проживает в качестве собственника, нанимателя либо на иных законных основаниях, с возложением запретов и осуществлением за ним контроля.

Кроме этого, в связи в возникающими на практике при избрании и применении данной меры пресечения проблемами, в ч. 14 ст. 107 УПК РФ были внесены изменения, позволяющие решить вопросы, связанные с использованием технических средств контроля. Так, в случае отказа подозреваемого от применения к нему аудиовизуальных, электронных и иных технических средств контроля или умышленного повреждения, уничтожения, нарушения целостности указанных средств либо совершения им иных действий, направленных на нарушение функционирования применяемых к нему аудиовизуальных, электронных и иных технических средств контроля, суд по ходатайству следователя или дознавателя, а в период судебного разбирательства по представлению контролирующего органа может изменить эту меру пресечения на более строгую.

Продолжая совершенствовать правовое регулирование применения домашнего ареста, законодатель Федеральным законом «О внесении изменений в статью 72 Уголовного кодекса Российской Федерации» от 03.07.2018 г. № 186-Ф3 ввел правовую норму, согласно которой время нахождения лица под домашним арестом засчитывается В срок содержания лица под стражей до судебного разбирательства и в срок лишения свободы из расчета два дня нахождения под домашним арестом за один день содержания под стражей или лишения свободы. Это позволило достичь справедливого назначения наказания, так как уравнение срока домашнего ареста со сроком содержания лица под стражей не соответствовало бы социальной справедливости.

Анализ исторического развития в российском уголовном судопроизводстве домашнего ареста как меры пресечения позволяет сделать следующие выводы:

1. Домашний арест как мера пресечения впервые был включен в правовые источники в первой половине XIX в. (Свод законов 1832 года).

2. Домашний арест последовательно включался во все последующие уголовно-процессуальные законы, за исключением УПК РСФСР 1960 г. Российскому уголовно-процессуальному институту мер пресечения присуща историческая предрасположенность к включению в свой состав домашнего ареста. 
3. В российском уголовно-процессуальном законодательстве отсутствовала регламентация оснований, условий и пределов применения данной меры пресечения, а также процедуры ее применения и механизма контроля за ее исполнением. Необходимо отметить, что в настоящее время указанные проблемы применения домашнего ареста по УПК РФ также не разрешены в полном объеме. Так, требует дальнейшего совершенствования регламентация порядка избрания данной меры пресечения, исполнения судебного решения об избрании домашнего ареста, а также осуществления контроля за выполнением наложенных судом на подозреваемого, обвиняемого запретов.

4. Несмотря на продолжительный исторический опыт законодательного регулирования домашнего ареста, обширный практический опыт его применения отсутствует. Одной из причин такого положения является недостаточная разработанность механизма избрания, применения и контроля за его исполнением.

\section{ЛИТЕРАТУРА}

1. Шадрин В.С. Обеспечение прав личности при расследовании преступлений. - Волгоград, 1997. 230 с.

2. Фойницкий И.Я. Курс уголовного судопроизводства. - Т. 2. - Изд. 3-е, - Спб., 1910.607 с.

3. Российское законодательство X-ХХ вв. Т. 8: Судебная реформа. М. Юрид. лит., 1991. 496 с.

4. Свод законов Российской империи. - ст. 135 ч. 2 т. XV. - Спб., 1892.

5. Кистяковский А.Ф. 0 пресечении обвиняемому способов уклоняться от следствия и суда. 196 с.

6. Розин Н.Н. Уголовное судопроизводство. Пособие к лекциям. Рига. 1924. - С. 361.

7. Кистяковский А.Ф. Указ. соч. - С.109.

8. Российское законодательство X-XX веков. Том 8. Судебная реформа. М., 1991.

9. Духовской М.В. Русский уголовный процесс. М., Посмертное издание. 1905. 448 с.

10. Люблинский П.И. Меры пресечения: (комментарий к ст. 143-161 УПК РСФСР). М., 1926. 56 с.

11. Кузьмин-Караваев В.Д. Пресечение способов уклонения от следствия и суда. Спб., 1902.59 с.

12. Декрет о суде 22 ноября (5 декабря) 1917 г. Декреты Советской власти. Т.І. М., Гос.изд-во полит. Литературы, 1957.

13. Давыдов П.М. Меры пресечения в советском уголовном процессе : автореферат дис. ... канд. юрид. наук. Л., 1953. 15 с.

14. Уголовно-процессуальный кодекс РСФСР. Утвержден постановлением 3-й сессии ВЦИК IX созыва от 25 мая 1922 г. // Собрание узаконений, 1922. № 20-21. ст. 230.

15. История законодательства СССР и РСФСР по уголовному процессу и организации суда 1917-1954 гг. Сборник документов. Под ред. члена-корр. Академии наук СССР Голубинского С.А. - М.: Гос. изд. юрид. лит., 1955. 468 с.

16. Там же. - С. 279.

17. Люблинский П.И. Указ. соч. - С. 48-49.

18. Строгович М.С. Уголовный процесс: Учебник для юридических вузов. - М.: Изд. НКЮ СССР, 1940. 311 с.

19. Балтабаев К.Т. Домашний арест в уголовном судопроизводстве республики Казахстан: Автореф. дисс... канд. юрид. наук. - М., 2001. 15 с.

20. Каминская В.И. Охрана прав и законных интересов граждан в уголовно-процессуальном праве // Советское государство и право. 1968. № 10. - С. 28.

21. Постановление Верховного Совета РСФСР от 24 октября 1991 г. № 1801-1 «0 концепции судебной реформы в РСФСР» // Ведомости Верховного Совета РСФСР. - 1991. № 44. - Ст. 1435 / Постатейные материалы к новому Уголовно-процессуальному кодексу Российской Федерации / Под ред. А.П. Рыжакова. - М.: ИНФРА-М, 2003.

22. Овчинников Ю.Г. Понятие, цели и сущность домашнего ареста как меры пресечения в уголовном судопроизводстве России // Следователь. М., 2003, № 5. - С. 33.

23. Зубков А., Крючкова Н. Кто и за что попадает в СИЗО // Преступление и наказание. 2000. № 9. С. 42.

24. Григорьева А.Е. Вопросы теории и практики избрания следователями органов внутренних дел отдельных мер пресечения: залога и домашнего ареста // Автореф. дис... канд. юрид. наук. Красноярск, 2009. 22 с.

(с Фирсов Владимир Григорьевич (firsov_vg65@mail.ru).

Журнал «Современная наука: актуальные проблемы теории и практики» 